\title{
Psychological Characteristics and Household Savings Behavior: The Importance of Accounting for Latent Heterogeneity ${ }^{1}$
}

\author{
Patrick Gerhard a, b \\ Joe J. Gladstone ${ }^{c}$ \\ Arvid O. I. Hoffmann b, d, * \\ a Maastricht University, School of Business and Economics, P.O. Box 616, 6200 MD Maastricht, The Netherlands \\ b Network for Studies on Pensions, Aging and Retirement (Netspar), P.O. Box 90153, 5000 LE Tilburg, The \\ Netherlands \\ ${ }^{c}$ University College London, School of Management, Level 38 One Canada Square, Canary Wharf, London, E14 \\ 5AA, United Kingdom \\ ${ }^{\mathrm{d}}$ University of Adelaide, Adelaide Business School, 10 Pulteney Street, SA 5005, Adelaide, Australia
}

\begin{abstract}
We employ a finite mixture model with maximum likelihood (ML) estimation to analyze latent heterogeneity in the relationship between psychological characteristics and household savings behavior. In a one-step ML estimation approach, we estimate a class membership model and a behavioral model of the classes jointly. Adopting this approach enables us to simultaneously assess how socio-demographic characteristics affect class membership probabilities and estimate class-specific regression coefficients, to test whether psychological characteristics predict savings behavior differently across latent classes. We apply this approach to a representative sample of UK households $(n=3,382)$ and identify two different latent classes: striving versus established households. We find that the relationship between psychological characteristics and savings behavior differs across these two classes, demonstrating the importance of accounting for latent heterogeneity when studying the drivers of savings behavior. Our results have implications for policymakers attempting to improve household savings behavior.
\end{abstract}

JEL Classification: D14; G02; G11

Keywords: Consumer Financial Decision-Making; Finite Mixture Model; Household Finance; Latent Class; Latent Heterogeneity; Individual Differences; Psychological Characteristics; Savings Behavior; Unobserved Heterogeneity.

* Corresponding author: Tel: +61(0)883134223. E-mail: arvid.hoffmann@adelaide.edu.au (Arvid O. I. Hoffmann).

\footnotetext{
${ }^{1}$ All authors contributed equally and are listed in alphabetical order. We would like to thank the Co-Editor, Joachim Winter, and two anonymous Reviewers for their constructive feedback and guidance. We thank seminar participants at the University of Adelaide Business School, Queensland University of Technology (QUT), RMIT University, Flinders University Business School, and the University of Western Australia Business School for helpful comments.
} 


\section{Introduction}

Prior research highlights the important contribution of psychological characteristics in explaining household savings behavior (e.g., Antonides et al., 2011; Loibl et al., 2011; Lunt and Livingstone, 1991). However, such research often assumes that the effect of psychological characteristics is the same across socio-demographic or socio-economic groups. Yet, it is also possible that psychological characteristics influence an individual's propensity to save differently based on life-cycle stage, gender, education level, or income - factors which themselves also influence savings behavior (e.g., Alessie and Lusardi, 1997; Brown and Taylor, 2014; DeVaney et al., 2007; Horioka and Watanabe, 1997; Lee et al., 1997; Mosca and McCrory, 2016; Wärneryd, 1999a).

To accommodate for these differences across groups, previous studies have either divided their samples based on observable attributes such as age, gender or marital status, and then analyzed the resulting subsamples in isolation, or instead utilized regression interaction terms (e.g., Brown and Taylor, 2014; Cho et al., 2014; Nyhus and Webley, 2001). However, the complex associations between psychological characteristics and savings behavior across different groups of individuals are likely to be overlooked when using these standard multivariate techniques. Indeed, prior research has argued that observable characteristics, such as gender or age, are by themselves insufficient to capture heterogeneity adequately (see e.g., Wedel and Kamakura, 2000). We therefore propose a different approach. Instead of a priori segmenting survey respondents based on observable characteristics, we explicitly accommodate for the role of latent (i.e., unobserved) heterogeneity in savings behavior by applying a finite mixture model.

Finite mixture models uncover latent heterogeneity by estimating the proportions of

distinct behavioral types in a population and allocating each individual to one endogenously defined behavioral type, characterized by a unique set of parameter values (Bruhin et al., 2010). 
These behavioral types can be interpreted as different segments, and are referred to as "classes". Using a finite mixture model, it is possible to simultaneously assess how socio-demographic variables affect class membership probabilities and estimate class-specific regression coefficients, to test whether psychological characteristics predict household savings behavior differently across latent classes. That is, finite mixture models can estimate a class membership model and a behavioral model of the classes jointly (for details, see McLachlan and Peel, 2000). These models allow for the objective identification of latent classes, and therefore provide the potential for a more accurate understanding of the variation which exists in savings behavior across groups (i.e., latent classes). Indeed, our findings indicate considerable heterogeneity in the influence of psychological characteristics across latent classes, suggesting that what motivates one group of individuals to save, does not (necessarily) motivate other groups to do the same.

Our objective in applying a finite mixture model is to more accurately identify the psychological characteristics driving savings behavior. Doing so is important, as an individual attempting to optimize their financial resources must look further than just their immediate consumption and consider trade-offs far into the future. The decision to defer consumption today and save for the future is central to economic theories of utility-maximization and is one of the most consequential decisions consumers make (Zhou and Pham, 2004). Savings act as a critical tool which households use to achieve financial goals and maintain financial well-being (Donnelly et al., 2012; Findley and Caliendo, 2015; Otto, 2013). Given the extant literature on hyperbolic discounting (Laibson, 1997), ongoing changes in government policy leading to an increased selfresponsibility to manage retirement savings mean that understanding the drivers of individuals' savings behavior is becoming ever more important, as some groups are likely to become increasingly vulnerable to failing to smooth their consumption over time (van Rooij et al., 2011). 
This paper makes several contributions to the literature on household finance and the individual differences which shape consumer financial decision-making. First, we introduce an innovative methodological approach to the ongoing debate on the psychological and sociodemographic predictors of household savings behavior. By highlighting the importance of unobserved heterogeneity, the results of the finite mixture model offer a possible explanation of why previous research - which focused on average effects in a population - has often found contradictory results on the role of psychological characteristics in explaining savings behavior. Second, by using a representative sample of the UK, our findings provide insights into the behavior of real population groups. These insights could help guide policymakers in deciding which psychological characteristics to target when attempting to improve savings behavior among specific sub-groups of citizens. As such, our results contribute to the debate on how psychological theories can inform public policy (e.g., Lynch and Wood, 2006). Third, while previous studies have typically examined the effect of psychological characteristics in isolation of each other, we aim to provide a more holistic perspective on the determinants of savings behavior. To do this, we systematically examine the joint effect on household savings behavior of not only the Big Five personality traits, self-control, and financial literacy, but also variables that have received less attention in the household finance literature, but seem equally relevant, such as optimism, attitudes towards savings, and promotion- versus prevention-focused savings goals.

Our study reveals several novel relationships between socio-demographic and psychological characteristics, which highlight the importance of understanding latent heterogeneity in household financial behavior. For example, while lower openness to experience and higher self-control are associated with a greater accumulation of savings in a class (or segment) we describe as "established" (i.e., those who are older and higher-income), we do not find similar effects in a class we describe as "striving" (i.e., those who are younger and lower- 
income). In contrast, for those in the striving class, setting savings goals is a far greater predictor of savings outcomes compared to those in the established class. These findings support the argument that different psychological characteristics - such as self-control - will be more or less influential on savings behavior depending on an individual's environment and life-cycle stage.

The remainder of this paper is structured as follows. Section 2 reviews prior literature. Section 3 introduces the data set we use in our analyses and presents an overview of the finite mixture model methodology we use to examine latent heterogeneity in savings behavior. Section 4 presents our results. Section 5 discusses these results. Section 6 summarizes the theoretical and practical implications of the results, presents limitations of the current investigation together with future research opportunities, and concludes on how future applications of finite mixture models could enrich our understanding of consumer financial decision-making and household finance.

\section{Literature Review}

\subsection{Factors Predicting Household Savings Behavior}

Putting aside money today, in order to save for the future, is a complex process determined by a wide range of factors. Traditionally, economists have conceptualized savings as what is left over from disposable income after consumption (Lunt and Livingstone, 1991). Prominent examples include the life-cycle hypothesis of saving (Modigliani and Brumberg, 1954; Modigliani, 1986) and the permanent income hypothesis (Friedman, 1957), which assume households are primarily concerned with maintaining consumption over the long-term. This means that if current income is reduced below average expected lifetime income, households will decrease their savings, and borrow to finance consumption. A more recent development, the buffer-stock model of consumption, pioneered by Deaton (1991) and Carroll (1997), predicts a high correlation of consumption with income regardless of expected future income, and assumes that consumers will 
save more when they are subject to more uncertainty ("precautionary saving"). In contrast, extant research in psychology provides a large number of concepts and theories for use in describing, explaining, and predicting savings behavior (see e.g., Wärneryd, 1999a; Canova et al., 2005). A few examples are the Big Five personality traits (e.g., Nyhus and Webley, 2001), attitudes towards saving (e.g., Davies and Lea, 1995), and self-control (e.g., Thaler and Benartzi, 2004).

While previous research has typically focused on a small number of predictors of savings, we instead aim to holistically and simultaneously assess many of the key psychological drivers of household savings behavior. The drivers of savings behavior that we investigate are financial literacy, the Big Five personality traits, self-control, optimism, attitudes towards savings, and promotion- versus prevention-focused savings goals (regulatory focus). ${ }^{1}$ We include these variables based on a review of the relevant literature on consumer financial decision-making and household finance, which identified them as central to understanding the differences regarding savings behavior across households. In this regard, we draw from research across a range of social science disciplines, including psychology, consumer behavior, economics, and finance.

While the finite mixture model methodology we employ in our analysis is data-driven, and the main purpose of this paper is to investigate the advantages of identifying different (latent) classes of households and analyzing the differential impact of psychological characteristics on savings behavior across these classes, it is still possible to have expectations about the effects of these psychological characteristics on savings behavior based on previous research. Table 1 provides an overview of key prior findings and our overall expectations based on these findings.

\section{--- Table 1 here ---}

\footnotetext{
${ }^{1}$ Although beyond the scope of this study due to data limitations, other relevant variables for household savings behavior relate to how consumers deal with time and the future, including variables such as time horizon (Wärneryd, 1999b), consideration of future consequences (Joireman et al., 2005), and time preference (Frederick et al., 2002).
} 


\subsection{Interactions between Psychological and Socio-Demographic Characteristics}

A challenge in understanding a complex behavior such as a household's savings is that models of behavior must not only contend with the complexity of two distinct factors (i.e., psychological and socio-demographic characteristics), but also account for the interaction between these factors. As socio-demographic characteristics shape the choices available to a person, this will, in turn, moderate when and how psychological characteristics predict behavior. Early influential work by Katona (1975) conceptualized saving money as a function of two sets of factors - the ability to save and the willingness to save. This is an important distinction - just because someone wants to save, does not mean that he or she can, and vice-versa. Indeed, while self-control has been linked to higher saving rates (e.g., Thaler and Benartzi, 2004), it might not be associated with higher savings in those who lack the financial resources to save. This ability to save will depend on factors such as an individuals' life-cycle stage, household size, income level, and the financial products available to them. Indeed, Bertrand et al. (2006) argue that the financial behavior of low-income consumers is more controlled by the circumstances independent of their intentions.

Differentiating between the willingness and the ability to save suggests that psychological characteristics will influence savings outcomes only when certain environmental conditions are met. This notion is supported by previous research illustrating how psychological characteristics interact with socio-demographic factors in influential ways. Mosca and McCrory (2016) studied how personality traits contributed to wealth accumulation in older groups, finding that individuals scoring higher on conscientiousness accumulate more wealth. However, they also found this relationship to only be significant for those at the lower end of the wealth distribution. This suggests that for those with higher levels of wealth, the role of other factors beyond personality become greater drivers of wealth accumulation. For example, one explanation is that higher-wealth individuals are likely to receive more generous pension contributions from their 
employer, meaning wealth accumulation may become less dependent on active choices for these individuals. Similarly, Cobb-Clark et al. (2016) investigated wealth accumulation across different income segments in Australia, studying the effects of locus of control. Their results suggested that locus of control had a greater influence on wealth accumulation for lower-income segments.

These examples highlight previous work which has investigated how psychological characteristics might influence savings behavior differently across socio-demographic groups. The advantage of using a finite mixture model approach is that we do not have to make a priori decisions on how to classify individuals by arbitrarily defining groups based on gender, marital status, wealth level, or income. Instead, we utilize the latent structure in the data to segment the sample according to what best fits the underlying regression model. In so doing, we aim to achieve a clearer understanding about the heterogeneity in the associations between psychological characteristics and savings behavior, and thereby help explain the current literature's lack of consensus and develop new opportunities for theory development and testing.

In the next sections, we briefly summarize and review each of these psychological drivers of savings behavior, thereby providing a rationale for their inclusion in our finite mixture model.

\subsection{Financial Literacy}

Financial literacy characterizes an individual's knowledge of basic financial concepts (Lusardi, 2008), and has been identified as a key variable to explain variation in a household's tendency to accumulate wealth (e.g., van Rooij et al., 2011). Individuals who are financially literate have the capacity to make more informed choices regarding financial matters, such as whether and how much to save (e.g., Stango and Zinman, 2009). Grasping basic financial concepts, such as the effect of compounded interest on the value of one's savings, is indispensable in understanding the importance of starting to save early for distant goals such as retirement. Similarly, knowledge 
about the costs of credit is invaluable in deciding whether to save for unexpected expenditures, such as those related to the breakdown of home appliances, or to take up credit to cover such costs. A significant percentage of households, however, do not understand basic concepts within personal finance, at least as measured through standard financial literacy tests. In fact, Klapper et al. (2015) show that only $57 \%$ of US and $67 \%$ of UK households can be considered financially literate in this regard. These figures are concerning, as not understanding basic financial concepts can adversely impact both a consumer's health and welfare (see e.g., Lusardi and Mitchell, 2007).

\subsection{The "Big Five" Personality Traits}

The "Big Five" model is the dominant paradigm for the measurement of personality traits. It originates from psychology and has become increasingly applied in economic research. The five personality traits are agreeableness, conscientiousness, extraversion, neuroticism, and openness to experience. McCrae and John (1992) provide an overview of the model. While several studies have used the Big Five to try and predict savings behavior, to date, the findings lack consensus on which of the personality traits are most-closely related to savings behavior and in what way.

Brown and Taylor (2014), for example, analyzed data from the British Household Panel Survey. They focused on the effect of the Big Five on financial outcomes, in particular on the amounts of unsecured debt and savings. The authors split their dataset into single persons and couples, and analyzed these groups separately. Overall, the authors found that specific personality traits are significantly associated with debt and asset holdings. However, they also found a large variation across their sample, with personality traits being associated with financial outcomes depending on both the type of household and the types of debt and assets. For example, the authors found a consistent negative relationship between conscientiousness and unsecured debt holdings, while also finding extraversion to have a negative association with asset holdings, but 
only for those living as a couple. Contrary to earlier work by Nyhus and Webley (2001), which found that neuroticism negatively affected savings, Brown and Taylor (2014) did not find any effect of neuroticism. As another example of the lack of consensus in the current literature, Mosca and McCrory (2016) find a positive relationship between extraversion and wealth accumulation in The Irish Longitudinal Study on Ageing, which is at odds with results from Nyhus and Webley (2001), who document a negative relationship of extraversion with savings.

Apart from having direct effects on savings behavior, it is important to note that personality traits can also have indirect effects, such as through income (see Borghans et al., 2008).

\subsection{Self-Control}

Self-control refers to an individual's capacity to control their impulses, emotions, desires, and actions in order to protect a valued goal (e.g., having a financially secure retirement) or resist a temptation (e.g., spending money on non-essential items). Self-control is the process of selfregulation in contexts involving a clear trade-off between long-term interests and immediate gratification (Bernheim et al., 2015; Thaler and Shefrin, 1981; Vohs et al., 2012). There is large variation in individuals' capacities for self-control, and those with less of it are less likely to save for the future and more likely to give in to temptations to spend today (cf. Thaler and Benartzi, 2004). Indeed, having poor self-control is associated with lower credit scores (Arya et al., 2013).

As well as a direct relationship between self-control and savings outcomes, self-control may also have indirect effects, such as through income. Research has found a positive relationship between self-control and higher income (Haushofer and Fehr, 2014), and various authors have attempted to explain this phenomenon. Within economics, Bernheim, Ray, and Yeltekin (2015) argue that poverty can be self-perpetuating, by undermining an individual's capacity for self-control. In contrast, work in developmental psychology finds that exposure to 
poverty in childhood may adversely affect children's socio-emotional adjustment through its impact on self-regulatory skills (Aber, Jones, and Cohen, 2000; Raver, 2004). Another recent perspective is that poverty forces people to spend time thinking about what they do not have, leaving less mental bandwidth for more abstract thought, such as planning for the future (Mullainathan and Shafir, 2013). Wealth (or the lack of it) can thus be an important environmental factor in influencing psychological processes and prior literature suggests multiple mechanisms through which self-control may influence savings behavior across the life-cycle.

\subsection{Optimism}

Optimism can be conceptualized as a generalized positive expectation about future events (Scheier, Carver, and Bridges, 1994). The degree to which individuals are optimistic about the future can influence their savings behavior, as individuals who are optimistic about future prospects will be less likely to believe they need to allocate money to save for future negative life events. Indeed, Vanden Abeele (1988) shows a negative relationship between short-term savings and consumer optimism using Katona's index of consumer expectations, which was later developed into the well-known University of Michigan Consumer Sentiment Index. Similarly, analyzing a different data set, van Raaij and Gianotten (1990) indicate that households with more

optimistic expectations about their financial situation tend to save less. Finally, Puri and Robinson (2007) found that individuals who are overly optimistic about their future prospects may not allocate sufficient money to precautionary savings, as they do not feel the need to save.

\subsection{Attitude towards Savings}

An attitude is "a relatively enduring organization of beliefs, feelings, and behavioral tendencies towards socially significant objects, groups, events or symbols” (Hogg and Vaughan, 2005: 150). 
Attitudinal factors are important drivers of a household's financial decisions. Furnham (1985) showed that household attitudes towards saving are not necessarily unidimensional and involve such factors as beliefs about the benefits versus pointlessness of saving, how one should save, whether saving secures wealth, and the self-denial that is implicit in saving. Savings attitudes are typically deeply rooted and learned early in life (Wärneryd, 1999b). Importantly, Furnham and Goletto-Tankel (2002) find a positive correlation between individuals' attitudes towards saving and their actual savings behavior, including the amount of money saved. Davies and Lea (1995) showed how attitudes towards saving up versus using credit to buy something correlate with socio-demographic (e.g., age) and psychological characteristics (e.g., locus of control). Their findings suggest that the effect of attitudes may vary across (socio-demographic) groups, reinforcing the need to examine the role of latent heterogeneity in explaining savings behaviors.

\subsection{Promotion- versus Prevention-Focused Savings Goals}

Individuals have different motivations to save (Canova et al., 2005). Early work by Keynes (1936) categorized these motivations into eight types: precautionary, life-cycle, intertemporal substitution, improvement, independence, enterprise, bequest, and avarice. These motives were reproduced by Browning and Lusardi (1996), who also added an additional "downpayment" motive (i.e., saving money in order to accumulate a sufficient deposit to buy a house or other durable goods). One common theme among these motivations is that because savings decisions are typically made to fulfil goals that are distant in time, they will be guided by processes of selfregulation (Brockner and Higgins, 2001). In this regard, the psychology literature distinguishes between a promotion versus a prevention system (see e.g., Zhou and Pham, 2004). The promotion system relies on approach strategies when regulating toward desirable ends (e.g., the pursuit of ideal situations and aspirations). In contrast, the prevention system, which originates in 
the regulation of security needs, relies on avoidance strategies when regulating toward desirable ends (e.g., the pursuit of oughts, such as the fulfilment of responsibilities and obligations).

Within household savings behavior, the promotion system invokes the desire to achieve financial gains, whereas the prevention system invokes the desire to avoid financial losses. The latter motivation corresponds to the precautionary motive as mentioned by Keynes (1936). Precautionary savings provide households with an emergency cushion in the case of a sudden loss or an unexpected spike in expenditures. In contrast, the former motivation corresponds to the improvement motive as described by Keynes (1936). Importantly, Browning and Lusardi (1996) recognize that there likely is heterogeneity in savings goals, suggesting that the wealthy might have different motives to save from the less wealthy. It is also possible that different life-cycle stages will be more closely associated with one system than another. Indeed, according to the buffer-stock model of consumption (Deaton, 1991; Carroll, 1997), it could be expected that individuals have prevention-focused savings goals until they have the desired buffer of savings. Therefore, there is likely to be an interaction between individuals' regulatory focus in terms of their savings goals and important socio-demographic characteristics such as their age and income.

\section{Data and Methodology}

\subsection{Data Collection}

Our data source is a unique household survey administered in 2013 by a large independent charity in the UK and designed in collaboration with one of the study authors. The survey investigates the household savings behavior of 4,170 UK individuals. Conducted by a specialized UK polling organization, the survey is representative of the overall UK population in terms of socio-demographics and was run online, via telephone, and in person to ensure a full representation of different groups. It contains questions on household savings, as well as several 
socio-demographic variables, including age, gender, income, and educational attainment. The survey also measures self-assessed financial literacy, self-control, optimism, savings attitude, and the Big Five personality traits. Item order was randomized to prevent any ordering effects. Table 2 provides an overview of all the variables and scales we use, as well as descriptive statistics.

The survey utilizes a stepwise approach, containing several questions with an exit-clause or which redirect respondents to a later question in the survey. In particular, the survey included a screener question to make sure everyone who answered the survey was either solely or jointly responsible for their household's finances and could thus be considered the "head of household." This question was: “Are you either solely or jointly responsible for your household's finances? If you live in a multi-person household (e.g., students, sharers), and are responsible for your own finances please tick yes." Of the 4,170 respondents, 266 answered "No" or "Don't know" and were excluded from the analysis. Furthermore, regarding the question on total household savings, respondents had the option to respond with "Don't know" or "Prefer not to say". Of the 3,904 respondents left after excluding those not responsible for their household finances, 522 responded in this way and were also excluded. We are thus left with 3,382 households for further analysis.

\section{--- Table 2 here ---}

\subsection{Measuring Household Savings Behavior}

We measure (self-reported) savings behavior using a question asking respondents about their total household savings. We use this measure because it captures the aggregated outcome of all saving decisions for a household and is often used in the literature (Nyhus and Webley, 2001). To ensure all respondents answered the question using the same definition of savings, the following introductory text was inserted before the question: "We'd now like to ask you some questions about the way that your household saves. If you live in a multi-person household (e.g., students, 
sharers), please answer on your own behalf when asked about your household. Again, by savings we mean cash or investments that can be turned into cash at short notice. Please note that this means we are not asking about saving into a pension or other long-term investments." This definition is similar to the concept of "liquid savings" by Nyhus and Webley (2001). The actual question was: "Please indicate the total amount of savings your household has at the moment".

\subsection{Measuring Household Psychological Characteristics}

To ensure reliability, we conduct a factor analysis on all constructs that we employ in this research. A list of individual item wordings, individual item loadings, and values for the reliability measure Cronbach's alpha (Cronbach, 1951) for all constructs is provided in Table 2. For the analyses, each scale is calculated as the equally weighted average of its respective items.

Optimism is measured using Scheier et al.'s (1994) LOT-R scale, the "Life Orientation Test - Revised". Four questions are "filler" items, and after removing these from the analysis, the remaining six items load sufficiently high on a single factor without noteworthy cross-loadings. Cronbach's alpha is 0.86 , providing evidence for internal consistency of the optimism measure.

Self-control is measured as in Tangney et al. (2004). Factor analysis reveals a singlefactor solution with satisfactory item loadings after eliminating three out of ten items. There are no significant cross-loadings and internal consistency is high with a Cronbach's alpha of 0.85 .

The Big Five personality traits were assessed using a fifteen-item scale taken from the British Household Panel Survey which Brown and Taylor (2014) use to examine the effect of the Big Five on the amounts of unsecured debt and savings of British households. The Big Five is a five-factor model of personality traits, which have been established as stable and reliable constructs (Cobb-Clark and Schurer, 2012). Due to a mistake in the survey execution, one question was left unusable for the purposes of analysis. Therefore, fourteen items measure how 
individuals exhibit the traits agreeableness, conscientiousness, extraversion, neuroticism, and openness to experience. Factor loadings are reasonable and Cronbach's alpha is generally sufficient, ranging between 0.56 and 0.77 . One exception is the scale measuring conscientiousness, the only trait measured using two instead of three items, which has a Cronbach's alpha of 0.43 . Although the latter reliability coefficient seems low by traditional standards, past research suggests that these alpha coefficients underestimate the actual reliability of these scales due to their brevity (Donnellan and Lucas, 2008; Lucas and Donnellan, 2011).

We measured promotion- versus prevention-focused savings goals by categorizing motivations for saving according to their regulatory focus. The survey included eleven items inspired by Zhou and Pham (2004), asking respondents about the reasons why they save. We recruited 94 individuals via Amazon's Mechanical Turk, who were briefed about the two selfregulation systems and instructed to classify items as belonging to either a promotion- versus a prevention-focused savings goal. Results of this classification are summarized in Appendix A1. Seven items are classified as promotion-focused goals, four as prevention-focused goals. In our analyses, we use two count variables for each respondent, indicating how many savings goals he or she selected that are classified as either promotion or prevention, respectively. A disadvantage of this measure is that we cannot establish that a person with more savings goals should be more motivated to save compared with a person with fewer savings goals. In particular, the subjective weights that participants place on the importance of individual savings goals will also determine their motivation to save. However, in the absence of information on these subjective weights, we believe the count variables serve as a useful approximation of whether participant's savings goals were promotion- versus prevention-focused. As the promotion versus prevention measure represents a formative scale, there is no Cronbach's alpha to report (see e.g., Hair et al., 2009). 
The survey also measured self-assessed financial literacy, using five items inspired by Lynch et al. (2010) and similar to Dholakia et al. (2016). Factor analysis confirms a single factor, and the Cronbach's alpha of the financial literacy scale is high at 0.83 . The survey also included a savings attitude measure inspired by Davies and Lea (1995) and Watson (2003), which contains two items. Factor analysis indicates a single factor, and Cronbach's alpha is satisfactory at 0.66 .

\subsection{Measuring Household Socio-Demographic Characteristics}

The survey measured several socio-demographic characteristics of respondents. We measured age in years, based on asking respondents about their date of birth. We measured gender by asking respondents whether they identified as male or female. We measured income by asking respondents the following question: "What is the combined annual income of your household, prior to tax being deducted?" We measured household size by asking respondents the following question: "Including yourself how many people in total live in your household?" We measured education by asking respondents the following question: "What is the highest educational level you have achieved to date?" In the analyses, we use a dummy for having a university education.

\subsection{The Finite Mixture Model Methodology}

Finite mixture models are employed to classify observations; adjust for clustering; and model unobserved heterogeneity (for a detailed review of these models, see McLachlan and Peel, 2000). In finite mixture modeling, the observed data are presumed to belong to unobserved subpopulations named classes, and mixtures of regression models are utilized to model the outcome of interest, which in our study is total household savings. Using finite mixture models, it is possible to estimate a class membership model and a behavioral model of the classes jointly. An important aspect of using finite mixture models is that uncovering latent heterogeneity may 
result in finding regression coefficients which differ in sign across classes. Finite mixture models constitute probabilistic models combining two or more density functions. In a finite mixture model, the observed responses $y$ are presumed to originate from $g$ distinct classes $f_{1}, f_{2}, \ldots, f_{g}$ in proportions $\pi_{1}, \pi_{2}, \ldots, \pi_{g}$. The density of a $g$-component mixture model can be written as:

$$
f(y)=\sum_{i=1}^{g} \pi_{i} f_{i}\left(y \mid x^{\prime} \beta_{i}\right)
$$

where $\pi_{i}$ is the probability for the $i$ th class, $0 \leq \pi_{i} \leq 1$ and $\sum \pi_{i}=1$, and $f_{i}(\cdot)$ represents the conditional probability density function for the observed response in the $i$ th class model.

The multinomial logistic distribution is used to model the probabilities for the latent classes. The probability for the $i$ th latent class is specified by:

$$
\pi_{i}=\frac{\exp \left(\gamma_{i}\right)}{\sum_{j=1}^{g} \exp \left(\gamma_{j}\right)}
$$

where $\gamma_{i}$ is the linear prediction for the $i$ th latent class. By default, the first latent class constitutes the base level, so that $\gamma_{1}=0$ and $\exp \left(\gamma_{1}\right)=1$.

We use Stata 15's “fmm” procedure (StataCorp., 2017), which fits finite mixture models via maximum likelihood estimation using the EM algorithm. The likelihood is computed by combining the conditional likelihoods from each latent class weighted by the associated latentclass probabilities. See McLachlan and Peel (2000) for further details on finite mixture modeling.

\section{Results}

In this section, we present evidence on unobserved heterogeneity in savings behavior, obtained through fitting a finite mixture model in a one-step maximum likelihood (ML) estimation approach with socio-demographic covariates that model the probability of class membership. That is, we estimate a class membership model and a behavioral model of the classes jointly. To 
do so, we use Stata 15 's finite mixture model regression (i.e., the "fmm: regress" procedure) alongside a latent class probability estimation (i.e., the "lcprob" option) (StataCorp., 2017). We first motivate the appropriate number of classes. We then present the finite mixture model results, which indicate both how the socio-demographic characteristics predict class membership probabilities, and how the psychological characteristics impact savings behavior across classes.

\subsection{Model Selection}

Model estimation starts with two classes and is repeated for an ever-increasing number of classes. To ensure the size of each class remains meaningful for interpretation given the sample size, we stop the procedure after seven classes. We choose the appropriate number of classes based on how the different models score regarding model fit and various information criteria, see Table 3. A two-class finite mixture model has minimum values for the Akaike Information Criterion (AIC), the Consistent Akaike Information Criterion (CAIC), and the Bayesian Information Criterion (BIC) and is thus selected. In line with the general recommendations of Bruhin et al. (2010) as well as Cameron and Trivedi (2005), we also assess whether the selected two-class model has classes that are well-separated from each other as indicated by the entropy statistic proposed by Ramaswamy et al. (1993); are balanced in terms of their relative size; and are meaningfully identifiable in terms of how the various socio-demographic characteristics (e.g., age, education, income) predict class membership probabilities. The two-class model features balanced class sizes; with class 1 containing $51 \%$ of respondents and class 2 containing $49 \%$. Also, the socio-demographic characteristics predict class membership probabilities meaningfully. Finally, the two-class model has an entropy statistic of 0.81, indicating that the classes are wellseparated from each other. The entropy statistic is a relative measure that is bound between 0 and 
1 (Ramaswamy et al., 1993). A value which is close to 1 indicates that the posterior probabilities are well separated (i.e., it is easy to classify observations accurately into distinct groups/classes).

--- Table 3 here ---

\subsection{How Socio-Demographic Characteristics Predict Class Membership Probabilities}

Table 4 presents results from the finite mixture model on how the socio-demographic characteristics predict the probability of belonging to a particular class. The membership probability results help provide meaningful labels to each of the two classes. Class 1 is the base outcome. Being older, married, university-educated, and on a higher income have a significantly positive impact on the probability of a household to belong to class 2 , while living in a household with more members, having dependent children, and being female have a significantly negative impact on the probability of a household to belong to class 2. Given these effects, in particularly regarding age, education, and income, we label class 1 as "the striving" and class 2 as "the established." In the next section, we will describe and interpret differences between these two classes regarding the impact of the psychological characteristics on household savings behavior.

--- Table 4 here ---

\subsection{How Psychological Characteristics Impact Household Savings Behavior Across Classes}

Table 5 presents regression coefficients from the finite mixture model explaining total household savings. ${ }^{2}$ To address the skewness in the distribution of this variable, we follow prior household savings literature (Nyhus and Webley, 2001) and take the natural log of total household savings. To accommodate for the fact that some households have zero savings, we add 1 to the actual

\footnotetext{
${ }^{2}$ The psychological characteristics have a similar impact on household savings behavior when we include income as additional independent variable in the finite mixture model, with income positively affecting total household savings.
} 
value of this variable before taking the natural $\log .{ }^{3}$ Because of the logarithmic transformation of the dependent variable, the reported regression coefficients reflect the percentage change in total household savings as a result of a one-unit change in the respective independent variable.

\section{--- Table 5 here ---}

Agreeableness is significantly negatively associated with total household savings, both for the striving and the established. However, the effect of agreeableness on total household savings is significantly stronger for the striving than for the established. For the striving, a one-point increase in agreeableness corresponds to a $36 \%$ reduction in total household savings, while the effect is only around $13 \%$ for the established. The findings regarding the impact of agreeableness on total household savings complement previous work in other areas of financial behavior, where recent research has found that agreeable people earn less and have lower credit scores than their less agreeable peers (Bernerth, Taylor, Walker, and Whitman, 2012; Judge et al., 2014). The results also extend previous findings within the household savings literature. In particular, neither Nyhus and Webley (2001) nor Brown and Taylor (2014) found a significant effect of agreeableness. Nyhus and Webley (2001) did provide a rationale for why agreeable people might save less. They argue that agreeableness describes people's propensity to act pro-socially towards others, and this concern for others might translate into generosity in terms of gift-giving, intervivos transfers, or charitable giving. In contrast, less agreeable individuals may be more likely to keep their money for themselves, and will thus be able to build up higher household savings.

Conscientiousness is significantly negatively associated with total household savings for the established, but not for the striving. For the established, a one-point increase in

\footnotetext{
${ }^{3}$ All results are similar when we add 10 to the actual value of total household savings instead of 1 before taking the log.
} 
conscientiousness corresponds to an $8.3 \%$ reduction in total household savings. At first, this finding might seem surprising, given that conscientiousness is associated with a tendency to plan, be organized, task- and goal-oriented, and to delay gratification (Nyhus and Webley, 2001) tendencies which intuitively should increase savings outcomes. However, recall that our measure of total household savings focuses on "liquid savings", such as money held in a checking account, or investments that can be turned into cash at short notice. Therefore, one explanation for this finding is that more conscientious individuals indeed plan more for long-term savings goals such as retirement, but do so by investing in "illiquid savings" that have higher expected returns, such as real estate, while holding comparatively less in "liquid savings", such as cash, that have lower expected returns. In contrast, less conscientious individuals might have shorter planning horizons, and therefore only save through "residual savings", meaning that they save whatever they do not spend from their available income in a given pay period (cf. Katona, 1975). Residual savings is included in our definition of total household savings, while illiquid savings is not, and therefore this could explain why conscientious people are found to save less. The results extend previous work by Nyhus and Webley (2001) and Brown and Taylor (2014), which did not distinguish between different classes of households, and found no effect of conscientiousness.

Both for the established and the striving, there is a significantly negative relationship between extraversion and household savings. For the established, scoring one point higher on the scale for extraversion corresponds to a $6.4 \%$ reduction in total household savings, while for the striving the effect is $11.4 \%$. The negative effect of extraversion on total household savings is consistent with the results reported by Brown and Taylor (2014), who also found a significant negative association between extraversion and a household's asset levels. One mechanism which could explain why extraversion is negatively related to savings is the tendency for extraverts to be more concerned with social status (Roberts and Robins, 2000). For example, extraverts 
actively seek out status at work (Barrick, Stewart, and Piotrowski, 2002). Households can express their status through discretionary expenditures (i.e., "keeping up with the Joneses"), decreasing the resources available to save for the future. Indeed, the stronger relationship between savings and extraversion in the striving group is consistent with recent research using customer bank account data which shows that low-income extraverts spend a greater proportion of their money on high-status goods compared to other groups (Landis and Gladstone, 2017). Alternatively, Nyhus and Webley (2001) suggest that extraverts' disposition towards spending time with others could explain this relationship. This is because more frequent interactions with other people are typically also associated with additional expenditures. Inviting people home, visiting other homes, and going out involves spending in one way or another, reducing one's opportunity to save. Furthermore, a wider circle of friends may expose extraverts to consumption patterns or social comparisons that also make them less inclined to save, thereby explaining this relationship.

Openness to experience is significantly negatively associated with total household savings for the established, but not for the striving. A one-point increase in openness to experience corresponds to a $7.3 \%$ reduction in total household savings. This finding builds on those by Mosca et al. (2016), who report a negative, but insignificant association between openness to experience and wealth, but do not distinguish between different classes of households. These authors argue that facets of this personality trait include curiosity, enjoyment of novelty, and imagination, which may lead households scoring high on this trait to consume more (e.g., visits to the theatre or art galleries, international travel), reducing their ability to build up higher household savings, and thus explaining the negative relationship between openness to experience and total household savings. The difference in the effect of openness to experience across the two classes might be driven by those in the striving group having fewer resources to allow them to engage in activities that stimulate the senses and satisfy the desire for novelty and curiosity to the 
extent they would wish. For example, the striving may choose not to indulge their desire to see new places or countries due to budgetary constraints, leading to an absence of an effect of this personality trait on total household savings, while for the established, pursuing such activities is much less restricted, leading them to engage in consumption activities which limit their savings.

Self-control - which is often associated with increases in the rate at which people save for the future (e.g., Thaler and Shefrin, 1981; Thaler and Benartzi, 2004) - is significantly and positively associated with total household savings for the established. An additional point on the self-control scale amounts to a $16.4 \%$ increase in total savings for these households. In contrast, we find that self-control has no significant effect on household savings for the striving. This suggests self-control may only contribute to determining savings outcomes for those who have the financial opportunities to save. For example, as established households face fewer financial constraints, this means they have more discretionary expenditures they can choose to defer into the future, or spend in the present period. As those with greater self-control will resist immediate temptations to consume, they will achieve greater savings rates. Self-control can work for these individuals in that it helps them to be able to resist immediate consumption temptations. For the striving, however, given their higher levels of financial constraints (and thus smaller amount of discretionary expenditures), giving in to immediate consumption temptations may not even be an option, and this would explain why self-control is not related to their total household savings. In other words, self-control only impacts household savings in the presence of opportunities to save. These findings regarding the effect of self-control on savings build on Katona's (1975) theory of saving, which distinguishes between individuals' ability to save and their willingness to save.

Both for the striving and the established, we find that more optimistic individuals hold less in savings. This finding is consistent with prior literature which views optimism as a generalized positive expectation about future events (Scheier, Carver, and Bridges, 1994), 
meaning households who are optimistic about future prospects do not believe they need to allocate money to save for future negative life events. These results are also consistent with other previous research, such as by Vanden Abeele (1988), who shows a relationship between shortterm savings and consumer optimism, and van Raaij and Gianotten (1990), who find that consumers with more optimistic expectations have a lower willingness to save. The effect of optimism on total household savings is significantly stronger for the striving than for the established group. For the former, a one-point increase in optimism corresponds with an almost $57 \%$ reduction in total household savings, while for the latter, the effect is only around $16 \%$. A potential explanation for this difference in effect size is that the relatively low income of those in the striving group makes it harder to save money, which translates into a greater reduction in savings for more optimistic households, who thus perceive a lower need to save for the future.

Financial literacy, which is typically associated with higher savings levels (Lusardi and Mitchell, 2007; van Rooij et al., 2011), is found to have a strong, positive relationship with total household savings, both for the established as well as for the striving. Again, the effect is significantly stronger for the striving than for the established. For the striving, an additional point on the financial literacy scale is associated with an almost $67 \%$ increase in total household savings, while the effect is around 35\% for the established. As such, those in the striving group may be in a position to benefit to a greater degree from higher levels of financial sophistication.

For both the striving and the established, more positive savings attitudes are associated with higher household savings. Having a more favorable attitude towards savings might make it easier to save as the benefits are clearer and there is less of a barrier to overcome when convincing oneself to save. In line with process models of attitude-behavior relations (e.g., Fazio, 1986), this result suggests that a positive inclination towards saving benefits its actual execution. Moreover, this finding is consistent with previous studies that find that a household's attitude 
towards savings has a strong impact on its actual savings behavior (e.g., Furnham and GolettoTankel, 2002). Again, the effect is significantly stronger for the striving than for the established group. For the striving group, a one-point increase in savings attitude corresponds to an increase of total household savings of $69 \%$, while for the established the effect on savings is around $33 \%$.

The impact of savings goals differs again between the two classes. Promotion-focused savings goals relate to objectives such as saving to build up a deposit to buy a property, while prevention-focused savings goals relate to objectives such as saving to reduce the impact of future financial burdens, such as a car repair. For the established group, savings goals that are promotion-focused are associated with an increase in total household savings, while preventionfocused savings goals are associated with having less in total household savings. In particular, having an additional promotion goal corresponds to an increase in total household savings of almost $20 \%$, while having an additional prevention goal corresponds to a decrease in total household savings of around $15 \%$. One potential explanation for this result concerns the types of products people use to financially protect themselves. Individuals concerned about preventing negative financial outcomes might save to protect themselves from financial harm through relatively illiquid instruments, such as life insurance, instead of cash or cash-like instruments. Our measure of liquid savings considers the latter, but not the former type of savings. An alternative explanation for this finding is that prevention goals are more frequently employed by those living with financial difficulties, which are experienced even by more affluent groups (Lusardi, 2009). Therefore, the objective to save to avoid financial harm might characterize those living in financial constraints, which then explains the differences in savings within this class. This explanation would also be consistent with the predictions of the buffer-stock model of consumption (Deaton, 1991; Carroll, 1997). Finally, a related explanation is that the established might only be worried about their future (and thus focus on prevention goals) if they have 
previously experienced adverse financial circumstances, such as a divorce or family death, which helps explain the observed differences in total household savings.

In comparison, both promotion- and prevention-focused savings goals are positively related to household savings for the striving. Having an additional promotion (prevention) goal corresponds to an increase in household savings of almost 99\% (127\%). For the striving, having specific savings goals, regardless of whether they are focused on trying to achieve gains or avoid losses, promotes greater savings. This effect might be explained by the fact that having a savings goal makes the relatively abstract notion of "saving money" more tangible, while having a reason to save could also act as a commitment device which increases the motivation to follow through in putting aside money, even with a limited household budget. Ashraf et al. (2006) support the notion that goals can act as commitment devices, while Gugerty (2007) discusses how commitment devices might be especially valuable for the savings behavior of the less affluent.

\section{Discussion of Results}

Our findings demonstrate the importance of accounting for latent heterogeneity in models predicting savings behavior from psychological characteristics. Comparing the two latent classes provides contrasting evidence to some previous theories of savings. For example, Katona's (1975) work highlighted the importance of distinguishing between the ability to save and the willingness to save. Based on Katona's (1975) theory, one could expect psychological characteristics to have a larger effect for the "established" group, since they have more discretionary income than "the striving" and therefore a higher ability to save (so willingness should be more important in this group). In our paper, however, we find the opposite effect, in that psychological characteristics seem to matter more for the "striving" than the "established", based on a comparison of the sizes of the regression coefficients across these two classes. Our 
findings are in line with those of Mosca and McCrory (2016), who found that the effect of personality traits on wealth accumulation was only significant for those at the lower end of the wealth distribution, and those of Cobb-Clark et al. (2016), who found that the psychological characteristic of locus of control had a greater influence on wealth accumulation for lowerincome segments than for higher-income segments. Together with ours, these results suggest that psychological characteristics are stronger predictors of financial behavior for lower-income and lower-wealth groups than for higher-income and higher-wealth groups. Thus, while more affluent people might save regardless of their psychological characteristics, less affluent people seem to be more influenced by their individual characteristics when deciding on such financial choices.

We find that psychological characteristics do not always influence savings behavior similarly across different groups of individuals. For example, openness to experience is negatively associated with total household savings, but only for the established. Similarly, while financial literacy positively influences total household savings for both the established and the striving, self-control only has a positive impact on household savings for the established. The economic effect sizes of these psychological characteristics also vary substantially across the different groups of households. Previous work has frequently found inconsistent relationships between the Big Five personality traits and savings outcomes; the variation across sociodemographic groups (i.e., latent classes) as reported in this paper may help explain these findings.

Exploring the differences in how psychological characteristics relate to savings behavior can provide new theoretical insights. Savings goals, for example, no matter whether they are promotion- or prevention-focused, are positively related to total household savings for the striving, while there is more differentiation in the relationship between types of savings goals and total household savings for the established. This finding suggests that for less affluent groups, having a savings objective per se acts as a commitment device to save, in the spirit of Gugerty 
(2007) and Ashraf et al. (2006). A study by Kast et al. (2012) on the effectiveness of self-help groups and peer pressure as commitment devices for precautionary savings suggests that especially the social dimension of such commitment devices are effective in increasing savings.

Combined with the strong effect of financial literacy on total household savings for the striving, interventions to improve financial outcomes in low-income groups might therefore particularly benefit from trying to improve their perceived need as well as motivation to save, either through financial training, or initiatives such as savings clubs, which can act as commitment devices. Recent work on the impact of financial education on downstream financial behaviors suggests that traditional forms of classroom training have only limited effectiveness, and point to the need of providing just-in-time financial training through, for example, coaching (Fernandes et al., 2014). In this regard, Linardi and Tanaka (2013) stress the critical role of focusing on building individuals' capacity to save, for example, through offering career advice. It is thus important to facilitate both individuals' willingness and ability to save (cf. Katona, 1975).

Finally, a more positive attitude towards savings is associated with higher total household savings for both the striving and the established, indicating it is a powerful motivator to improve household savings behavior. The aforementioned personal coaching or savings clubs could help households develop a more positive savings attitude and thus build more savings. Research suggesting that social and financial education interventions in schools can have a positive effect on savings attitudes are encouraging in this regard (Supanantaroek, Lensink, and Hansen, 2017).

\section{Implications, Limitations, and Conclusion}

\subsection{Implications for Policymakers}

Understanding heterogeneity in household savings behaviors and the psychological motivators of this behavior is becoming ever more important as the self-responsibility of individuals to manage 
long-term savings, such as their pensions, increases (cf. van Rooij et al., 2011). Although there have consistently been found to be differences across individuals in savings behavior, a systematic study on the effect of psychological characteristics across different groups is lacking.

The results of this study contribute to understanding the differential impact of psychological characteristics across various groups of individuals. The findings have implications for policymakers, who in order to promote savings behavior in sub-groups less predisposed to save, could incorporate an appreciation of the complexity of the relationships between psychological characteristics and savings behavior. Currently, most policymakers are concerned with using financial literacy programs to try and improve household savings rates. However, recent research indicates that, overall, formal financial education has only limited effectiveness of improving financial behavior long-term and studies point to an important role of just-in-time financial training as well as psychological characteristics to understand the true effects of financial literacy interventions on downstream financial behavior (cf. Fernandes et al., 2014).

Indeed, Bertrand et al. (2006) suggest that standard public policy interventions aimed at improving financial literacy may be ineffective when financial behavior is controlled more by circumstances than by intentions, as would be the case for more vulnerable consumers. Our study complements existing research by indicating that it is not only important for policy makers to be aware of the psychological characteristics of the individuals whose financial literacy they are trying to improve, but also to realize that there is often latent heterogeneity across groups in terms of the impact psychological characteristics have on savings behavior. For example, interventions to improve self-control might be effective, but only for certain sub-groups of the population, and not for the population as a whole. We find that for a more vulnerable group of society, which we label as the striving, instead of focusing on self-control, policy makers interested in stimulating 
savings behavior could look into ways to stimulate the adoption of a positive savings attitude as well as savings goals, which might act as commitment devices to follow through on intentions.

Policymakers often segment the population using their behavior and sometimes psychological characteristics to efficiently identify and target specific groups of interest. For example, the UK Financial Conduct Authority (2014) recently issued a report on consumer credit in which they segment individuals based on their credit usage and classify them into different borrower typologies. This segmentation reveals major differences in credit usage between segments. However, such approaches are limited in the sense that they only use observed behavioral differences and may overlook the latent heterogeneity in the data. Moreover, standard segmentation approaches may be potentially biased by the subjective perspectives of the investigators who may hold pre-conceived ideas about how to categorize groups. Applying a finite mixture model provides a more objective segmentation which is free from potential investigator bias. Should finite mixture models be applied more widely in studies on household financial behavior, specific patterns emerging across different samples of individuals will help in the development of new theory, as complex patterns will emerge and require novel explanations.

\subsection{Limitations and Future Research}

Our study has several limitations that should be taken into account when interpreting the findings, and which offer possible avenues for future research. First, instead of examining how socio-demographic characteristics affect the relationships between psychological characteristics and savings behavior, we could also have taken the opposite approach of examining how psychological characteristics affect the relationships between socio-demographic characteristics and savings behavior. However, a classification based on socio-demographics (particularly given the nationally representative sample that we analyze) is useful, because policymakers may be 
interested in targeting specific groups with interventions to improve savings. Knowing that one group (of younger, lower-income people) is motivated by a particular psychological characteristic, could help tailor specific messages or campaigns towards that group. Demographic information is accessible through databases such as the Census and government tax records, making it possible to use this information to plan public policy activities. In contrast, building a classification based on specific psychological characteristics would not be as straightforward or intuitive for policy makers, because databases of psychological characteristics are generally not available to them and would require fielding new, comprehensive surveys to gather these data.

Second, some of the previous inconsistencies across studies regarding the effects of psychological characteristics on household savings behavior may be caused not only by taking an average effect approach, but also by the use of different measures of psychological characteristics across studies. For example, while Brown and Taylor (2014) use the same short scale of items to measure the Big Five personality traits as we do, Mosca and McCrory (2016) use a longer scale.

Third, as with any cross-sectional study, one should be careful in drawing causal interpretations regarding the effect of psychological characteristics on household savings behavior. In particular, total household savings is something which is built over time as the product of both regular behaviors of putting aside money, and life changes such as inheritances. That is, parts of the reported household savings may be a result of decisions made long before the time of our study, or may not be a result of decisions at all (as with, for example, an inheritance).

Fourth, in our study we were interested in examining the different effects of promotionversus prevention-focused savings goals on total household savings and we measured how many of each of these goals respondents considered. Apart from the number of goals, however, respondents may also differ regarding the importance they attribute to the different savings goals. Although beyond the focus of the current study, this aspect may be addressed in future research. 
Fifth, in our study we only examined one aspect of savings behavior - total household savings. However, other aspects of savings behavior, such as monthly savings, or the age at which one starts to save are also relevant and may be studied in future research. Moreover, similar to earlier studies on household savings such as by Nyhus and Webley (2001), our measure of household savings focused on "liquid savings" such as cash or investments that can be turned into cash at short notice. However, households might use a variety of financial instruments to try and reach their financial objectives, including more "illiquid savings" such as life insurance or real estate. By including a broader assessment of the ways in which households save, future research could gain a more detailed insight into any trade-offs they might make in this regard.

Sixth, despite the high Cronbach's alpha which indicates a reliable construct, our measure of households' attitude towards saving could be interpreted as consisting of two separate components: an attitude towards saving and an attitude towards credit. Future research might examine the potentially different effect of these two attitudinal dimensions on savings behavior.

\subsection{Conclusion}

In conclusion, our study provides a novel set of results which indicate that the impact of psychological characteristics on savings behavior varies across different (socio-demographic) groups. The main implication of these findings is that it is important to explicitly take unobserved heterogeneity into account when studying the role of personality traits, savings goals, and other psychological characteristics in consumer financial decision-making, such as savings behavior. By applying the finite mixture model methodology to a new setting, we hope our research encourages future studies to consider the benefits of this approach in understanding the rich complexity of the relationships between socio-demographic and psychological characteristics. 


\section{References}

Aber, J. L., Jones, S., and Cohen, J. (2000). "The Impact of Poverty on the Mental Health and Development of Very Young Children.” In: C. H. Zeanah Jr. (Ed.), Handbook of Infant Mental Health (2nd ed., pp. 113-128). New York, NY: Guilford Press.

Alessie, R., and Lusardi, A. (1997). "Saving and Income Smoothing: Evidence from Panel Data." European Economic Review, 41(7): 1251-1279.

Antonides, G., de Groot, I. M., van Raaij, W. F. (2011). "Mental Budgeting and the Management of Household Finance.” Journal of Economic Psychology, 32(4): 546-555.

Arya, S., Eckel, C., and Wichman, C. (2013). "Anatomy of the Credit Score." Journal of Economic Behavior \& Organization, 95(November): 175-185.

Ashraf, N., Karlan, D., and Yin, W. (2006). "Tying Odysseus to the Mast: Evidence From a Commitment Savings Product in the Philippines." Quarterly Journal of Economics, 121(2): $635-672$.

Barrick, M. R., Stewart, G. L., and Piotrowski, M. (2002). "Personality and Job Performance: Test of the Mediating Effects of Motivation among Sales Representatives.” Journal of Applied Psychology, 87(1): 43-51.

Bernerth, J. B., Taylor, S. G., Walker, H. J., and Whitman, D. S. (2012). "An Empirical Investigation of Dispositional Antecedents and Performance-Related Outcomes of Credit Scores.” Journal of Applied Psychology, 97(2): 469-478.

Bernheim, B. D., Ray, D., and Yeltekin, S. (2015). "Poverty and Self-Control." Econometrica, 83(5): 1877-1911.

Bertrand, M., Mullainathan, S., and Shafir, E. (2006). "Behavioral Economics and Marketing in Aid of Decision Making Among the Poor.” Journal of Public Policy \& Marketing, 25(1): 8-23. 
Borghans, L., Duckworth, A. L., Heckman, J. J., and Ter Weel, B. (2008). "The Economics and Psychology of Personality Traits.” Journal of Human Resources, 43(4): 972-1059.

Brockner, J., and Higgins, E. T. (2001). "Regulatory Focus Theory: Implications for the Study of Emotions at Work." Organizational Behavior and Human Decision Processes, 86(1): 35-66.

Brown, S., and Taylor, K. (2014), "Household Finances and the 'Big Five' Personality Traits." Journal of Economic Psychology, 45: 197-212.

Browning, M., and Lusardi, A. (1996). "Household Saving: Micro Theories and Micro Facts." Journal of Economic Literature, 34(4), 1797-1855.

Bruhin, A., Fehr-Duda, H., and Epper, T. (2010). "Risk and Rationality: Uncovering Heterogeneity in Probability Distortion.” Econometrica, 78, 1375-1412.

Cameron, A. C., and Trivedi, P. K. (2005). "Microeconometrics: Methods and Applications." Cambridge: Cambridge University Press.

Canova, L., Manganelli Rattazzi, A. M., and Webley, P. (2005). "The Hierarchical Structure of Saving Motives.” Journal of Economic Psychology, 26(1): 21-34.

Carroll, C. D. (1997). "Buffer-Stock Saving and the Life Cycle/Permanent Income Hypothesis." Quarterly Journal of Economics, 112(1): 1-55.

Cho, S. H., Loibl, C., and Geistfeld, L. (2014). "Motivation for Emergency and Retirement Saving: An Examination of Regulatory Focus Theory." International Journal of Consumer Studies, 38(6): 701-711.

Cobb-Clark, D. A., and Schurer, S. (2012). "The Stability of Big-Five Personality Traits." Economics Letters, 115(1): 11-15.

Cobb-Clark, D.A., Kassenboehmer, S.C. and M. Sinning (2016). "Locus of Control and Savings.” Journal of Banking and Finance, 73(December): 113-130. 
Cronbach, L. J. (1951). "Coefficient Alpha and the Internal Structure of Tests.” Psychometrika, 16(3): 297-334.

Davies, E., and Lea, S. E. (1995). "Student Attitudes to Student Debt." Journal of Economic Psychology, 16(4): 663-679.

Deaton, A. (1991). “Saving and Liquidity Constraints.” Econometrica, 59(5): 1221-1248.

DeVaney, S. A., Anong, S. T., and Yang, Y. (2007). “Asset Ownership by Black and White Families." Journal of Financial Counseling and Planning, 18(1): 33-45.

Dholakia, U., Tam, L., Yoon, S., and Wong, N. (2016). "The Ant and the Grasshopper: Understanding Personal Saving Orientation of Consumers." Journal of Consumer Research, 43(1): 134-155.

Donnellan, M. B., and Lucas, R. E. (2008). "Age Differences in the Big Five across the Life Span: Evidence from Two National Samples." Psychology and Aging 23 (3): 558-566.

Donnelly, G., Iyer, R., and Howell, R. T. (2012). “The Big Five Personality Traits, Material Values, and Financial Well-Being of Self-Described Money Managers.” Journal of Economic Psychology, 33(6): 1129-1142.

Fazio, R. H. (1986). “How do attitudes guide behavior?” In Sorrentino, R. M. and Higgins, E. T. (Eds). Handbook of Motivation and Cognition: Foundations of Social Behavior, pp. 204-243, New York : Guilford Press.

Fernandes, D., Lynch Jr, J. G., and Netemeyer, R. G. (2014). "Financial Literacy, Financial Education, and Downstream Financial Behaviors.” Management Science, 60(8): 1861-1883.

Financial Conduct Authority (2014). "Consumer Credit and Consumers in Vulnerable Circumstances." Online available at: https://www.fca.org.uk/publications/research/consumercredit-and-consumers-vulnerable-circumstances, last accessed 27/01/2017. 
Findley, T. S., and Caliendo, F. N. (2015). "Time Inconsistency and Retirement Choice." Economics Letters, 129: 4-8.

Frederick, S., Loewenstein, G., and O’Donoghue, T. (2002). “Time Discounting and Time Preference: A Critical Review.” Journal of Economic Literature, 40(2): 351-401.

Friedman, M. (1957). “The Permanent Income Hypothesis.” In Friedman, M. (Ed). A Theory of the Consumption Function, pp. 20-37, Princeton, New Jersey: Princeton University Press.

Furnham, A. (1985). "Why do People Save? Attitudes to, Habits of, Saving Money in Britain." Journal of Applied Social Psychology, 15(5): 354-373.

Furnham, A., and Goletto-Tankel, M.-P. (2002). "Understanding Savings, Pensions and Life Assurance in 16-21-Year-Olds." Human Relations, 55(5): 603-628.

Gugerty, M. K. (2007). "You Can't Save Alone: Commitment in Rotating Savings and Credit Associations in Kenya," Economic Development and Cultural Change, 55(2), 251-282.

Hair, J. F., Black, W. C., Babin, B. J., and Anderson, R. E. (2009). “Multivariate Data Analysis ( $7^{\text {th }}$ edition).” New York: Pearson Higher Education.

Haushofer, J., and Fehr, E. (2014), “On the Psychology of Poverty,” Science, 344 (6186): 862-67. Hogg, M., and Vaughan, G. (2005). Social Psychology (4th edition). London: Prentice-Hall. Horioka, C. Y., and Watanabe, W. (1997). "Why Do People Save? A Micro-Analysis of Motives for Household Saving in Japan.” Economic Journal, 107(442): 537-552.

Judge, T. A., Livingston, B. A., and Hurst, C. (2012). "Do Nice Guys - and Gals - Really Finish Last? The Joint Effects of Sex and Agreeableness on Income." Journal of Personality and Social Psychology, 102(2): 390-407.

Kast, F., Meier, S., and Pomeranz, D. (2012). "Under-Savers Anonymous: Evidence on Self-Help Groups and Peer Pressure as a Savings Commitment Device.” NBER Working Paper No. 18417, Online available at http://www.nber.org/papers/w18417, last accessed 21/02/2017. 
Katona, G. (1975). Psychological Economics. New York: Elsevier.

Keynes, J. M. (1936). “The General Theory of Employment, Interest and Money.” London: MacMillan.

Klapper, L., Lusardi, A., and van Oudheusden, P. (2015). "Financial Literacy Around the World. Insights From The Standard \& Poor's Ratings Services Global Financial Literacy Survey.” Online available at https://responsiblefinanceforum.org/wp-content/uploads/2015/12/2015Finlit_paper_17_F3_SINGLES.pdf, last accessed 22/02/2017.

Kotov, R., Gamez, W., Schmidt, F., and Watson, D. (2010). "Linking "Big” Personality Traits to Anxiety, Depressive, and Substance Use Disorders: A Meta-Analysis.” Psychological Bulletin, 136(5): 768-821.

Laibson, D. (1997). "Golden Eggs and Hyperbolic Discounting." Quarterly Journal of Economics, 112(2): 443-477.

Landis, B., and Gladstone, J. (2017). "Personality, Income, and Compensatory Consumption: Low-Income Extraverts Spend More on Status.” Psychological Science, 28(10): 1518-1520.

Lee, A. Y., Aaker, J. L., and Gardner, W. L. (2000). "The Pleasures and Pains of Distinct SelfConstruals: The Role of Interdependence in Regulatory Focus." Journal of Personality and Social Psychology, 78(6): 1122-1134.

Lee, S., Hanna, S., and Siregar, M. (1997). “Children's College as a Saving Goal.” Journal of Financial Counseling and Planning, 8(1): 33-36.

Linardi, S., and Tanaka, T. (2013). "Competition as a Savings Incentive: A Field Experiment at a Homeless Shelter." Journal of Economic Behavior \& Organization, 95(November): 240-251.

Loibl, C., Kraybill, D. S., and DeMay, S. W. (2011). "Accounting for the Role of Habit in Regular Saving." Journal of Economic Psychology, 32(4): 581-592. 
Lucas, R. E., and Donnellan, M. B. (2011). "Personality Development across the Life Span: Longitudinal Analyses with a National Sample from Germany.” Journal of Personality and Social Psychology, 101(4): 847-861.

Lunt, P. K., and Livingstone, S. M. (1991). "Psychological, Social and Economic Determinants of Saving: Comparing Recurrent and Total Savings.” Journal of Economic Psychology, 12(4): 621-641.

Lusardi, A. (2008). "Household Saving Behavior: The Role of Financial Literacy, Information, and Financial Education Programs." NBER Working Paper No. 13824, Online available at http://www.nber.org/papers/w13824, last accessed 22/02/2017.

Lusardi, A. (2009). Overcoming the Saving Slump: How to Increase the Effectiveness of Financial Education and Savings Programs. Chicago, IL: The University of Chicago Press.

Lusardi, A., and Mitchell, O. (2007). "Financial Literacy and Retirement Preparedness: Evidence and Implications for Financial Education.” Business Economics, 42(1): 35-44.

Lynch, J. G., Netemeyer, R. G., Spiller, S. A., and Zammit, A. (2010). “A Generalizable Scale of Propensity to Plan: The Long and the Short of Planning for Time and for Money." Journal of Consumer Research, 37(1): 108-128.

Lynch, J. G., and Wood, W. (2006). 'Special Issue Editors' Statement: Helping Consumers Help Themselves." Journal of Public Policy and Marketing, 25(1): 1-7.

McCrae, R. R., and John, O. P. (1992), “An Introduction to the Five-Factor Model and Its Applications.” Journal of Personality, 60(2): 175-215.

Modigliani, F. (1986). "Life Cycle, Individual Thrift, and the Wealth of Nations." American Economic Review, 76(3): 297-313.

Modigliani, F. (1954). "Utility Analysis and the Consumption Function: An Interpretation of Cross-Section Data.” In: K. Kurihara (ed.), Post Keynesian Economics. London: G. Allen. 
Mosca, I., and McCrory, C. (2016). "Personality and Wealth Accumulation among Older Couples: Do Dispositional Characteristics Pay Dividends?” Journal of Economic Psychology, 56 (October): 1-19.

McLachlan, G., and Peel, D. (2000). “Finite Mixture Models.” New York: John Wiley and Sons. Mullainathan, S., and Shafir, E. (2013). "Scarcity: Why Having Too Little Means so Much.” New York: Henry Holt and Company.

Nyhus, E. K., and Webley, P. (2001). "The Role of Personality in Household Saving and Borrowing Behaviour." European Journal of Personality, 15(S1): 85-103.

Otto, A. (2013). "Saving in Childhood and Adolescence: Insights from Developmental Psychology." Economics of Education Review, 33: 8-18.

Petkoska, J., and Earl, J. K. (2009). "Understanding the Influence of Demographic and Psychological Variables on Retirement Planning.” Psychology and Aging, 24(1): 245-251.

Puri, M., and Robinson, D. T. (2007). “Optimism and Economic Choice.” Journal of Financial Economics, 86(1): 71-99.

Ramaswamy, V., Desarbo, W., Reibstein, D., and Robinson, W. (1993). “An Empirical Pooling Approach for Estimating Marketing Mix Elasticities with PIMS Data.” Marketing Science, 12(1): 103-124.

Raver, C. C. (2004). "Placing Emotional Self-Regulation in Sociocultural and Socioeconomic Contexts." Child Development, 75, 346-353.

Roberts, B. W., and Robins, R. W. (2000). "Broad Dispositions, Broad Aspirations: The Intersection of Personality Traits and Major Life Goals." Personality and Social Psychology Bulletin, 26(10), 1284-1296. 
Scheier, M. F., Carver, C. S., and Bridges, M. W. (1994). "Distinguishing Optimism From Neuroticism (and Trait Anxiety, Self-Mastery, and Self-Esteem): A Reevaluation of the Life Orientation Test.” Journal of Personality and Social Psychology, 67(6): 1063-1078.

Schulz, R., Bookwala, J., Knapp, J. E., Scheier, M., Williamson, G. M. (1996). "Pessimism, Age, and Cancer Mortality". Psychology and Aging, 11, 304-309.

Stango, V. and Zinman, J. (2009). "Exponential Growth Bias and Household Finance.” Journal of Finance, 64(6): 2807-2849.

StataCorp. (2017). “Finite Mixture Models Reference Manual.” College Station, TX: Stata Press.

Supanantaroek, S., Lensink, R., and Hansen, N. (2017). "The Impact of Social and Financial Education on Savings Attitudes and Behavior Among Primary School Children in Uganda." Evaluation Review, 41(6): 511-541.

Tangney, J. P., Baumeister, R. F., and Boone, A. L. (2004). "High Self-Control Predicts Good Adjustment, Less Pathology, Better Grades, and Interpersonal Success.” Journal of Personality, 72(2): 271-322.

Thaler, R. H., and Shefrin, H. M. (1981). “An Economic Theory of Self-Control.” Journal of Political Economy, 89(2): 392-406.

Thaler, R., and Benartzi, S. (2004). "Save More Tomorrow"TM: Using Behavioral Economics to Increase Employee Saving.” Journal of Political Economy, 112(S1): S164-S187.

Vanden Abeele, P., 1988. 'Economic Agents' Expectations in a Psychological Perspective'. In: W.F. van Raaij, G.M. van Veldoven and K.-E. Wärneryd (eds.), Handbook of Economic Psychology. Dordrecht: Kluwer. pp. 478-515.

van Rooij, M., A. Lusardi, Alessie, R. (2011). "Financial Literacy and Stock Market Participation.” Journal of Financial Economics, 101(2), 449-472. 
van Raaij, W. F., and Gianotten, H. J. (1990). “Consumer Confidence, Expenditure, Saving, and Credit.” Journal of Economic Psychology, 11(2): 269-290.

Vohs, K. D., Baumeister, R. F., and Schmeichel, B. J. (2012). "Motivation, Personal Beliefs, and Limited Resources all Contribute to Self-Control." Journal of Experimental Social Psychology, 48(4): 943-947.

Wärneryd, K.-E. (1999a). "The Role of Macroeconomic Psychology." Applied Psychology, 48(3): 273-296.

Wärneryd, K.-E. (1999b). "The Psychology of Saving: A Study of Economic Psychology." Cheltenham: Edward Elgar.

Watson, J. J. (2003). “The Relationship of Materialism to Spending Tendencies, Saving, and Debt.” Journal of Economic Psychology, 24(6): 723-739.

Wedel, M. and Kamakura, W. (2000). “Market Segmentation: Conceptual and Methodological Foundations." London: Kluwer, $2^{\text {nd }}$ edition.

Zhou, R., and Pham, M. T. (2004). "Promotion and Prevention across Mental Accounts: When Financial Products Dictate Consumers' Investment Goals." Journal of Consumer Research, 31(1): 125-135. 
Table 1: Psychological Characteristics and Savings Behavior

\begin{tabular}{|c|c|c|}
\hline Scale & Authors and Reported Direction of Effect & Expected Effect \\
\hline Financial Literacy & $\begin{array}{l}\text { Lusardi and Mitchell (2007) - positive } \\
\text { Stango and Zinman (2009) - positive } \\
\text { van Rooij et al. (2011) - positive }\end{array}$ & positive \\
\hline The Big Five & & \\
\hline Extraversion & $\begin{array}{l}\text { Nyhus and Webley (2001) - negative } \\
\text { Brown and Taylor (2011) - negative } \\
\text { Cobb-Clark et al. (2013) - no effect } \\
\text { Mosca and McCrory (2016) - positive }\end{array}$ & negative \\
\hline Openness to Experience & $\begin{array}{l}\text { Nyhus and Webley (2001) - no effect } \\
\text { Brown and Taylor (2011) - positive } \\
\text { Cobb-Clark et al. (2013) - positive } \\
\text { Mosca and McCrory (2016) - no effect }\end{array}$ & positive \\
\hline Conscientiousness & $\begin{array}{l}\text { Nyhus and Webley (2001) - no effect } \\
\text { Brown and Taylor (2011) - no effect } \\
\text { Cobb-Clark et al. (2013) - no effect } \\
\text { Mosca and McCrory (2016) - positive }\end{array}$ & positive \\
\hline Agreeableness & $\begin{array}{l}\text { Nyhus and Webley (2001) - negative } \\
\text { Brown and Taylor (2011) - no effect } \\
\text { Cobb-Clark et al. (2013) - negative } \\
\text { Mosca and McCrory (2016) - no effect }\end{array}$ & negative \\
\hline Neuroticism & $\begin{array}{l}\text { Nyhus and Webley (2001) - negative } \\
\text { Brown and Taylor (2011) - no effect } \\
\text { Cobb-Clark et al. (2013) - no effect } \\
\text { Mosca and McCrory (2016) - negative }\end{array}$ & negative \\
\hline Self-Control & Thaler and Benartzi (2004) - positive & positive \\
\hline Optimism & $\begin{array}{c}\text { Vanden Abeele (1988) - negative } \\
\text { van Raaij and Gianotten (1990) - negative } \\
\text { Puri and Robinson (2007) - negative }\end{array}$ & negative \\
\hline Attitude $t / w$ Savings & $\begin{array}{l}\text { Davies and Lea (1995) - positive } \\
\text { Furnham and Goletto-Tankel (2002) - positive }\end{array}$ & positive \\
\hline Promotion-Focused Savings Goals & Cho et al. (2014) - positive & positive \\
\hline Prevention-Focused Savings Goals & Cho et al. (2014) - positive & positive \\
\hline
\end{tabular}

\section{Note:}

This table provides a summary of findings from key literature regarding the effect of the psychological characteristics examined in this study on household savings behavior. Please note that the dependent variables are not always the same across the prior studies. 
Table 2: Scale and Variable Definitions

\begin{tabular}{|c|c|c|c|c|c|}
\hline Scale & Item Wording & Mean & $\begin{array}{l}\text { Std. } \\
\text { Dev. }\end{array}$ & $\begin{array}{l}\text { Item } \\
\text { Loading }\end{array}$ & $\begin{array}{l}\text { Cronbach's } \\
\text { Alpha }\end{array}$ \\
\hline The Big Five & $\begin{array}{l}\text { [answers recorded on a scale ranging from: (1) does not apply to me at all - (7) applies } \\
\text { to me perfectly] }\end{array}$ & & & & 0.72 \\
\hline \multirow[t]{3}{*}{ Agreeableness } & I see myself as someone who is sometimes rude to others* & 5.23 & 1.68 & 0.62 & 0.56 \\
\hline & I see myself as someone who is considerate and kind to almost everyone & 5.03 & 1.46 & 0.84 & \\
\hline & I see myself as someone who has a forgiving nature & 5.60 & 1.13 & 0.76 & \\
\hline \multirow[t]{2}{*}{ Conscientiousness } & I see myself as someone who does a thorough job & 5.80 & 1.08 & 0.81 & 0.43 \\
\hline & I see myself as someone who tends to be lazy* & 4.89 & 1.75 & 0.81 & \\
\hline \multirow[t]{3}{*}{ Extraversion } & I see myself as someone who is talkative & 4.27 & 1.67 & 0.84 & 0.72 \\
\hline & I see myself as someone who is outgoing, sociable & 4.46 & 1.59 & 0.86 & \\
\hline & I see myself as someone who is reserved* & 3.65 & 1.64 & 0.69 & \\
\hline \multirow[t]{3}{*}{ Neuroticism } & I see myself as someone who worries a lot & 4.39 & 1.78 & 0.88 & 0.77 \\
\hline & I see myself as someone who gets nervous easily & 3.91 & 1.82 & 0.85 & \\
\hline & I see myself as someone who is relaxed, handles stress well* & 3.65 & 1.60 & 0.75 & \\
\hline Openness to & I see myself as someone who is original, comes up with new ideas & 4.62 & 1.45 & 0.83 & 0.71 \\
\hline \multirow[t]{2}{*}{ Experience } & I see myself as someone who values artistic, aesthetic experiences & 4.64 & 1.60 & 0.75 & \\
\hline & I see myself as someone who has an active imagination & 5.18 & 1.42 & 0.82 & \\
\hline \multirow[t]{8}{*}{ Self-Control } & [answers recorded on a scale ranging from: (1) very much like me - (5) not at all like & & & & 0.85 \\
\hline & I have a hard time breaking bad habits & 3.30 & 1.16 & 0.65 & \\
\hline & I get distracted easily & 3.52 & 1.15 & 0.70 & \\
\hline & I say inappropriate things & 3.83 & 1.12 & 0.72 & \\
\hline & Pleasure and fun sometimes keep me from getting work done & 3.64 & 1.14 & 0.69 & \\
\hline & I do things that feel good in the moment but regret later on & 3.67 & 1.09 & 0.80 & \\
\hline & Sometimes I can't stop myself from doing something, even if I know it is wrong & 3.87 & 1.13 & 0.78 & \\
\hline & I often act without thinking through all the alternatives & 3.82 & 1.12 & 0.76 & \\
\hline \multirow[t]{7}{*}{ Optimism } & [answers recorded on a scale ranging from: (1) I disagree a lot-(5) I agree a lot] & & & & 0.86 \\
\hline & In uncertain times, I usually expect the best & 2.98 & 1.03 & 0.71 & \\
\hline & If something can go wrong for me, it will* & 3.05 & 1.17 & 0.75 & \\
\hline & I'm always optimistic about my future & 2.70 & 1.11 & 0.74 & \\
\hline & I hardly ever expect things to go my way* & 3.03 & 1.16 & 0.81 & \\
\hline & I rarely count on good things happening to me* & 3.12 & 1.15 & 0.77 & \\
\hline & Overall, I expect more good things to happen to me than bad & 2.66 & 1.09 & 0.80 & \\
\hline
\end{tabular}


Table 2: Scale and Variable Definitions - Continued

\begin{tabular}{|c|c|c|c|c|c|}
\hline Scale & Item Wording & Mean & $\begin{array}{l}\text { Std. } \\
\text { Dev. }\end{array}$ & $\begin{array}{l}\text { Item } \\
\text { Loading }\end{array}$ & $\begin{array}{l}\text { Cronbach's } \\
\text { Alpha }\end{array}$ \\
\hline \multirow[t]{6}{*}{ Financial Literacy } & $\begin{array}{l}\text { How would you assess... [answers recorded on a scale ranging from: (1) very low - } \\
\text { (7) very high] }\end{array}$ & & & & 0.83 \\
\hline & ... your overall financial knowledge & 4.68 & 1.47 & 0.86 & \\
\hline & ... your ability at math & 5.16 & 1.55 & 0.63 & \\
\hline & $\begin{array}{l}\ldots \text { your ability at dealing with day-to-day financial matters (e.g. checking your } \\
\text { accounts, managing payments, etc) }\end{array}$ & 5.69 & 1.39 & 0.74 & \\
\hline & ... your tendency to keep up with financial news & 4.13 & 1.80 & 0.79 & \\
\hline & $\ldots$ how engaged you feel with your finances & 4.94 & 1.64 & 0.83 & \\
\hline \multirow[t]{3}{*}{ Attitude t/w Savings } & [answers recorded on a scale ranging from: (1) definitely false - (5) definitely true] & & & & 0.66 \\
\hline & You should always save up first before buying something & 3.84 & 1.00 & 0.87 & \\
\hline & I try to avoid debt at all costs & 3.92 & 1.20 & 0.87 & \\
\hline Age: 18-24 & Indicator variable: $1=$ respondent being between 18 and 24 years old, $0=$ otherwise & 0.08 & & & \\
\hline Age: $25-34$ & Indicator variable: $1=$ respondent being between 25 and 34 years old, $0=$ otherwise & 0.16 & & & \\
\hline Age: $35-44$ & Indicator variable: $1=$ respondent being between 35 and 44 years old, $0=$ otherwise & 0.17 & & & \\
\hline Age: $45-54$ & Indicator variable: $1=$ respondent being between 45 and 54 years old, $0=$ otherwise & 0.20 & & & \\
\hline Age: 55-64 & Indicator variable: $1=$ respondent being between 55 and 64 years old, $0=$ otherwise & 0.17 & & & \\
\hline Age: $65+$ & Indicator variable: $1=$ respondent being 65 years or older, $0=$ otherwise & 0.23 & & & \\
\hline Income & Annual household income (in $£ \times 1,000$ ) & 26.36 & 17.22 & & \\
\hline Married & Indicator variable: $1=$ respondent married, $0=$ otherwise & 0.48 & 0.50 & & \\
\hline $\begin{array}{l}\text { High Education } \\
\text { (University) }\end{array}$ & Indicator variable: $1=$ respondent has attended university, $0=$ otherwise & 0.43 & 0.50 & & \\
\hline \# HHmembers & Number of people living in same household & 2.47 & 1.23 & & \\
\hline
\end{tabular}


Table 2: Scale and Variable Definitions - Continued

\begin{tabular}{|c|c|c|c|c|c|}
\hline Scale & Item Wording & Mean & $\begin{array}{l}\text { Std. } \\
\text { Dev. }\end{array}$ & $\begin{array}{c}\text { Item } \\
\text { Loading }\end{array}$ & $\begin{array}{c}\text { Cronbach's } \\
\text { Alpha }\end{array}$ \\
\hline Employed & Indicator variable: $1=$ respondent is full-time or part-time employed, $0=$ otherwise & 0.54 & 0.50 & & \\
\hline Child in Household & Indicator variable: $1=$ person of age $<18$ living in household, $0=$ otherwise & 0.28 & 0.45 & & \\
\hline Female & Indicator variable: $1=$ respondent being female, $0=$ otherwise & 0.50 & 0.50 & & \\
\hline Total Household Savings & Total household savings (in $£ \times 1,000$ ) & 18.32 & 26.45 & & \\
\hline
\end{tabular}

Note:

This table provides an overview of the scales used in this study, including all items that comprise the scales as well as how answers to the questions are recorded (in brackets). Each scale is calculated as the equally weighted average of its respective items. '*' denotes reverse coding of an item. Item loading indicates the individual item's factor loading. 
Table 3: Finite Mixture Model - Model Selection Criteria

\begin{tabular}{ccccc}
\hline $\begin{array}{c}\text { \# of Latent } \\
\text { Classes }\end{array}$ & $\begin{array}{c}\text { Log } \\
\text { Likelihood }\end{array}$ & AIC & CAIC & BIC \\
\hline 2 & $\mathbf{- 7 , 6 3 8}$ & $\mathbf{1 5 , 3 5 4}$ & $\mathbf{1 5 , 6 3 2}$ & $\mathbf{1 5 , 5 9 3}$ \\
3 & $-7,790$ & 15,704 & 16,146 & 16,084 \\
4 & $-7,974$ & 16,110 & 16,687 & 16,606 \\
5 & $-8,010$ & 16,244 & 17,042 & 16,930 \\
6 & $-8,133$ & 16,524 & 17,443 & 17,314 \\
7 & $-8,261$ & 16,848 & 18,010 & 17,847 \\
\hline
\end{tabular}

Note:

This table presents information on various model selection criteria for different numbers of latent classes, using the "fmm: regress" procedure with the option "lcprob" in Stata 15, which fits a finite mixture model with covariates that model the probability of class membership, allowing us to estimate a class membership model and a behavioral model of the classes jointly. AIC refers to the Akaike Information Criterion, CAIC refers to the Consistent Akaike Information Criterion, and BIC refers to the Bayesian Information Criterion. The minimum value for each model selection criterion is highlighted in bold, indicating that the appropriate number of latent classes in this case is two. 
Table 4: Finite Mixture Model - Probability of Class Membership

(1)

Probability of Belonging to

Class 2 Relative to Class 1

Age: 25-34

0.017

$(0.271)$

Age: $35-44$

0.056

(0.276)

Age: 45-54

$0.574 * *$

$(0.258)$

Age: 55-64

$1.715 * * *$

$(0.269)$

Age: 65+

$2.502 * * *$

$(0.281)$

Income (in $£ \mathbf{x 1 , 0 0 0 )}$

$0.063 * * *$

$(0.005)$

Married

$0.331 * * *$

(0.124)

High Education (University)

$0.491 * * *$

(0.112)

\# HHmembers

$-0.140 * *$

(0.067)

Employed

0.053

(0.140)

Child in Household

$-0.487 * * *$

(0.171)

Female

$-0.240 * *$

$(0.109)$

Note:

This table presents results on how socio-demographic characteristics predict the probability of class membership, using the "fmm: regress" procedure with the option "lcprob" in Stata 15, which fits a finite mixture model with covariates that model the probability of class membership, allowing us to estimate a class membership model and a behavioral model of the classes jointly. Class 1 is the base outcome. The coefficients in column (1) indicate how socio-demographic characteristics predict the probability of belonging to class 2 as compared to belonging to class 1 . "Age: $18-24$ " is omitted because of collinearity. Standard errors are in parentheses. ***, **, and * denote statistical significance at the $1 \%, 5 \%$, and $10 \%$ level, respectively. 
Table 5: Finite Mixture Model - Regression of Log Total Household Savings

\begin{tabular}{|c|c|c|c|}
\hline & $\begin{array}{c}(1) \\
\text { Class } 1 \\
\text { "The Striving" } \\
\text { InHHSav }\end{array}$ & $\begin{array}{c}(2) \\
\text { Class } 2 \\
\text { "The Established" } \\
\text { InHHSav }\end{array}$ & $\begin{array}{l}(3) \\
\text { Chi-Square Statistic for the } \\
\text { Difference between Regression } \\
\text { Coefficients in (1) versus (2) }\end{array}$ \\
\hline Agreeableness & $\begin{array}{c}-0.362 * * * \\
(0.074)\end{array}$ & $\begin{array}{c}-0.128 * * * \\
(0.033)\end{array}$ & $9.070 * * *$ \\
\hline Conscientiousness & $\begin{array}{l}-0.048 \\
(0.073)\end{array}$ & $\begin{array}{c}-0.083 * * * \\
(0.031)\end{array}$ & 0.210 \\
\hline Extraversion & $\begin{array}{l}-0.114 * \\
(0.061)\end{array}$ & $\begin{array}{c}-0.064 * * \\
(0.026)\end{array}$ & 0.620 \\
\hline Neuroticism & $\begin{array}{c}-0.031 \\
(0.061)\end{array}$ & $\begin{array}{c}0.036 \\
(0.027)\end{array}$ & 1.130 \\
\hline Openness to Experience & $\begin{array}{l}-0.077 \\
(0.064)\end{array}$ & $\begin{array}{c}-0.073 * * \\
(0.029)\end{array}$ & 0.000 \\
\hline Self-control & $\begin{array}{c}0.079 \\
(0.101)\end{array}$ & $\begin{array}{c}0.164 * * * \\
(0.049)\end{array}$ & 0.640 \\
\hline Optimism & $\begin{array}{c}-0.568 * * * \\
(0.102)\end{array}$ & $\begin{array}{c}-0.156 * * * \\
(0.045)\end{array}$ & $14.590 * * *$ \\
\hline Financial Literacy & $\begin{array}{c}0.668 * * * \\
(0.067)\end{array}$ & $\begin{array}{c}0.351 * * * \\
(0.033)\end{array}$ & $18.960 * * *$ \\
\hline Attitude $t / w$ Savings & $\begin{array}{c}0.694 * * * \\
(0.080)\end{array}$ & $\begin{array}{c}0.328 * * * \\
(0.037)\end{array}$ & $18.930 * * *$ \\
\hline Promotion & $\begin{array}{c}0.988 * * * \\
(0.088)\end{array}$ & $\begin{array}{c}0.196 * * * \\
(0.031)\end{array}$ & $75.270 * * *$ \\
\hline Prevention & $\begin{array}{c}1.272 * * * \\
(0.113)\end{array}$ & $\begin{array}{c}-0.151 * * * \\
(0.042)\end{array}$ & $145.600 * * *$ \\
\hline Log Likelihood & \multicolumn{2}{|c|}{$-7,638$} & \\
\hline$N$ & \multicolumn{2}{|c|}{3,382} & \\
\hline
\end{tabular}

Note:

This table presents regression coefficients from a finite mixture model, using the "fmm: regress" procedure with the option "lcprob" in Stata 15, which fits a finite mixture model with covariates that model the probability of class membership, allowing us to estimate a class membership model and a behavioral model of the classes jointly. Standard errors are in parentheses. 'InHHSav' abbreviates the natural logarithm of total household savings. Equality of regression coefficients across classes is tested using the postestimation "test" procedure in Stata 15, which reports chi-squares and significance levels of the differences. The relative class proportions are as follows: $50.62 \%$ of the sample falls into class 1 ("the striving") and $49.38 \%$ of the sample falls into class 2 ("the established"). ***, **, and * denote statistical significance at the $1 \%, 5 \%$, and $10 \%$ level, respectively. 


\section{Appendix A1: Classification of Savings Goals as Promotion- versus Prevention-Focused}

\section{Promotion- \\ Focused \\ (Aiming to \\ gain \\ Positive)}

(1)

For unexpected expenditures (a rainy day)

To pay for bills (e.g., gas, electricity, etc)

For a deposit to buy a property

For a planned purchase in the future (e.g., car, fridge, etc)

For planned maintenance costs in the future (e.g., car repairs, home renovation, etc)

For holidays or other leisure expenditures

To provide income in retirement (please note we are not referring to pension saving)

Because it's a good investment in the long-term

Because of a recent/upcoming event (e.g., marriage, birth of a child)

For a family-member's future (e.g., a child trust fund)

In order to repay a loan

\begin{tabular}{lcccc}
13 & 9 & $\mathbf{7 5}$ & 97 & $0.000^{* * *}$ \\
20 & 19 & $\mathbf{5 8}$ & 97 & $0.000^{* * *}$ \\
$\mathbf{8 7}$ & 8 & 1 & 96 & $0.000^{* * *}$ \\
$\mathbf{8 3}$ & 7 & 7 & 97 & $0.000^{* * *}$ \\
16 & 10 & $\mathbf{7 1}$ & 97 & $0.000^{* * *}$ \\
$\mathbf{8 8}$ & 7 & 2 & 97 & $0.000^{* * *}$ \\
$\mathbf{5 9}$ & 9 & 29 & 97 & $0.001 * * *$ \\
$\mathbf{6 8}$ & 20 & 9 & 97 & $0.000^{* * *}$ \\
$\mathbf{6 4}$ & 12 & 21 & 97 & $0.000^{* * *}$ \\
$\mathbf{6 9}$ & 12 & 16 & 97 & $0.000^{* * *}$ \\
27 & 16 & $\mathbf{5 4}$ & 97 & $0.002^{* * *}$ \\
\hline
\end{tabular}

\section{Note:}

This table provides an overview of all savings goals and how they are classified as promotion- versus preventionfocused. Ninety-seven individuals recruited on Amazon's Mechanical Turk classified 11 possible savings goals according to their fit to promotion, prevention, or neither of those categories. The first column displays the savings goal as stated in the survey. The following three columns ((1)-(3)) summarize the amount of times a certain savings goal was classified as belonging to a certain category. $\mathrm{N}$ is is the total number of respondents who classified the savings goals. Column (5) contains information about the p-value of a one-sample z-test to indicate statistically significant differences between columns (1) and (3). ' $* * *$ ' indicates significance at the $1 \%$-level. Bold numbers display how a given savings goal is ultimately categorized for usage in our analyses. 